Article

\title{
The Impact of Teamwork on an Organization's Performance: A Cooperative Game's Approach
}

\author{
Gholamreza Askari ${ }^{1}$, Nader Asghri ${ }^{1}$, Madjid Eshaghi Gordji ${ }^{1}$, Heshmatolah Asgari ${ }^{2}$, \\ José António Filipe ${ }^{3, * \mathbb{D}}$ and Adel Azar 4 \\ 1 Department of Mathematics, Semnan University, Semnan P.O. Box 35195-363, Iran; \\ g.askari@semnan.ac.ir (G.A.); nasghari@semnan.ac.ir (N.A.); meshaghi@semnan.ac.ir (M.E.G.) \\ 2 Department of Economy, Faculty of Literature and Human Sciences, Ilam University, \\ Ilam P.O. Box 69315-516, Iran; h.asgari@ilam.ac.ir \\ 3 Department of Mathematics, ISTA-Escola de Tecnologias e Arquitectura, Iscte-Instituto Universitário de \\ Lisboa, Information Sciences, Technologies and Architecture Research Center (ISTAR-IUL), Business \\ Research Unit-IUL (BRU-IUL), 1649-026 Lisbon, Portugal \\ 4 Department of Management, Faculty of Management \& Economy, Tarbiat Modares University, \\ Tehran P.O. Box 14155-4838, Iran; azara@modares.ac.ir \\ * Correspondence: jose.filipe@iscte.pt
}

Received: 15 September 2020; Accepted: 13 October 2020; Published: 16 October 2020

\begin{abstract}
In this article, we study the impact of teamwork on an organization's performance, considering a cooperative game's framework. To promote teamwork culture, performance indexes were considered both individually and collectively, and by comparing the scores that every employee earned individually and collectively, their differences became obvious. In this approach, a cooperative game's model was used in order to improve the organization's performance. The proposed model, in addition to evaluating the organization and employee's activities, implemented all payments, including overtime pay, rewards, etc., fairly and along with increasing performance and satisfaction. The cooperative approach created effective communications between employees and authorities and enhanced their motivation for teamwork. Moreover, results could be used for decisions related to employees (such as promotion, transition, firing, and secondment), analysis of training requirements, employees' development, and research and plan valuation. Our findings show that the collaborative coefficient (CC) is a key factor in increasing productivity and improving the efficiency of an organization in the long run. The collaborative coefficient is a new concept in teamwork that has rarely been considered in scientific research.
\end{abstract}

Keywords: collaborative coefficient; performance management; game theory; teamwork; Shapley value

\section{Introduction}

Human beings have long been considered for the beneficial, efficient, and fruitful use of their available abilities, possibilities, and resources. In the present era, this has become more serious than ever before. The limitation of available resources, the increase in population, and growing human needs and demands have made decision makers in the areas of economics, politics, and societal and organizational management give priority to productivity enhancement and performance management in organizations' plans. Performance management (PM) is the process of continuous feedback and communication between managers and employees that is used to achieve the strategic goals of an organization. The main purpose of performance management is to ensure that employees have acted effectively over the course of a year. Organizational progress is achieved by having people who are constantly looking for ways to work intelligently, both individually and organizationally. Increasing the effectiveness of human resources leads to increasing the efficiency of the organization. In many organizations, process improvement is 
pursued in order to grow and improve performance and move in the path of excellence [1]. Although these programs usually start with much enthusiasm and potential, they often fail to meet the expectations of the organization's senior management. This vacuum is usually the result of the model used by the organization's senior managers and is less related to the efforts of the executors of the model.

Performance management is a management tool that helps managers of a company or an organization to monitor and evaluate the quality of their employees. One of the goals of performance management programs is to create an environment in which people can make the best use of their abilities to provide the highest quality work with the highest efficiency and effectiveness. Performance management is an initiative that leads employees to achieve their goals and those of the organization. Organizations need to continually improve their performance in order to survive and thrive in a competitive world. Human resources can also be considered as one of the most important organizational resources. In recent years, organizations have paid more attention to their employees and put the search for ways to improve the work environment and encourage employees on their agenda [2]. This attention stems from the fact that a person is the "most valuable intelligent asset" of the organization. Organizations that lose their smart capital have little chance of survival. To value this huge asset, we need performance management, and especially performance appraisal.

Due to the multidimensional nature of the performance of organizations and a process management system (PMS) including financial and non-financial performance, a set of indicators was developed. Based on the PMS framework, there are different dimensions and performance characteristics in an organization and enterprise that need to be measured [3]. Pambreni et al. [4] indicate that total quality management (TQM) elements, namely customer focus, continuous improvement, strategically based elements, and total employee involvement, have positive and significant effects on the organization's performance.

Teamwork is very important for a good output and good communication among staff in the company [5]. A team may be described as a group of individuals who come together to achieve the same functions and goals to deliver outstanding services. The most famous teamwork theory is Bruce Tuckman's "team stages model" [6]. Teamwork is the manner of operating collaboratively with a group of individuals as a way to achieve an objective. One of the lost links in organizations is teamwork $[7,8]$. Many social theorists assess an organization's capability to develop coexistence and teamwork as one of the progress and success factors in achieving a high level of productivity [9,10]. Hamilton et al. [11] examined the impact of teamwork on productivity improvement and concluded that the adoption of teamwork and the implementation of collaborative skills improved workers' productivity by 14 percent on average, which are less valuable in individual production. In fact, when people collaborate together to perform a job and think and argue about it, a rich and comprehensive initial plan of the job is generated, and when the base of a job is inclusive and accurate, its productivity and enhancement are more visible $[12,13]$. Therefore, it can be said that with the gathering and cooperation of individuals, strong ideas and strong opinions are generated [14,15]. Karanja et al. [16] examined the effects of teamwork on the performance of a water service regulatory board and showed that teamwork had a significant effect on the organization's performance. Rajabali and Reuben [17] conducted a study on the effect of teamwork development and organizational performance at the Tile and Carpet Centre (T \& C) in Kenya. This study established and provided evidence that organizational success depends upon the interdependence recognized within teams and how vital it is for team members to understand their roles and work to achieve corporate goals, thus having a positive influence on organizational performance. Abuzid and Abbas [18] demonstrated that there is a direct positive significance of the components of teamwork and their impact on organizational performance and also a positive relationship with organizational support and a team leader's readiness in making teams effective and eventually improving the organizational performance in a public service institution in the Kingdom of Saudi Arabia. For more information, see previous studies on the effect of teamwork on organizational performance $[19,20]$.

In general, factors affecting an organization's performance can be divided into two categories: 
(a) External organizational factors: factors whose origin is outside public organizations and with effects on productivity are external organizational factors. The most important external organizational factors include social, economic, and cultural factors.

(b) Internal organizational factors: factors that are inside the public organizations and with effects on productivity are internal organizational factors. Among the most important internal organizational factors are manpower, organizational climate, wage and salary, promotion and rewards, organizational culture, and participation and teamwork. Based on the results presented above, the following hypothesis is proposed:

Hypothesis 1. Teamwork has a positive effect on the organization's performance.

One of the concepts addressed in game theory is cooperative games that emphasize teamwork. The basic concepts of game theory were introduced by Van Neumann in 1944 and created the foundations of the modern economy [21]. In 1950, John Nash introduced a new definition of equilibrium in games, which is a crucial concept in non-cooperative games [22,23]. Non-cooperative games are games in which all players appear independently in the game, and each player seeks to maximize his/her own interests [24,25]. In cooperative games, players, in order to achieve more benefits, choose cooperation instead of competition and agree to make coalitions and workgroups for choosing strategies that increase collective outcomes. Many of the national, regional, and even international disputes in which conflicts may result in imposing heavy costs on parties can be pursued through a cooperative game's model to reduce the costs. Allocation of public goods, exploitation of water resources, exploitation of oil wells, allocation of environmental costs, stock exchanges, commercial agreements, and international relations are examples of cases where the allocations of costs and benefits between players through cooperative game theory are much easier $[26,27]$. A cooperative game is one of the fairest ways upon which one can address allocating costs, incomes, wages, overtime amounts, and rewards by complying with the three principles of productivity, justice, and sustainability. Shapley in 1953 introduced the Shapley value as one competition concept to calculate the allocation of costs and benefits in a cooperative game [28]. In 1971, Shubik for the first time offered methods for applying cooperative game techniques to solve financial and accounting problems for companies and organizations [29]. Based on the results presented above, the following hypothesis is proposed:

Hypothesis 2. A cooperative approach has a positive effect on the organization's performance.

The main purpose of this study was to provide a model for evaluating the performance in organizations. In this regard, the conceptual model of research was presented to investigate the impact of factors affecting performance using game theory. In this model, in order to calculate performance, we considered eight factors affecting the main activities of employees such as speed, accuracy, skill, creativity, interaction and coordination, knowledge transfer and experience, motivation, and expression of ideas. Managers and assistants must determine the weight of intended indexes according to the scope of their activities and organizational goals. To promote collaborative work culture, performance assessment is based on the scores that each employee achieves in individual work and teamwork.

The paper is organized as follows: the following two sections are dedicated to the description of the performance calculation model (Section 2) and to the calculation of performance in teamwork (Section 3). In Section 4, we present an application of the model for the calculation and payment of overtime. Finally, Section 5 presents a discussion and our conclusions.

\section{Description Performance Calculation Model}

Performance can be the outcome accomplished by a person, team, organization, or process [30]. From an organizational point of view, evaluating the performance of employees is a necessary and undeniable task in measuring the progress of individuals in achieving organizational goals and missions. Performance appraisal provides awareness and feedback and determines the strengths and weaknesses of performance and the position of the organization in a turbulent environment full of environmental changes. In addition, performance management organizes individual and 
organizational behavior and improves the performance of individuals at the lower to upper levels of the organization. Research findings indicate that organizations with efficient and effective performance management have higher profits, better turnover, and higher productivity [31]. On the one hand, the performance of any organization is a function of the performance of the human resources of that organization and their interaction with the resources, facilities, and technology available in the organization. On the other hand, the performance of human resources depends on their motivation and ability. In addition, the ability of human resources is itself a function of job knowledge and skills in applying the mentioned knowledge in performing tasks and job activities. Furthermore, the motivation of human resources depends on the attitude of employees and the circumstances in which they work. Performance management can be defined as the process by which these functions are used in the organization. In other words, performance management is an integrated set of policies and actions that achieve goals by focusing on individual performance. The performance appraisal is a measure of an organization's effectiveness. If individual performance is improved, it is clear that the performance of the organization will also improve. Performance appraisal is a continuous managerial activity and, for this reason, managers constantly study and judge the behavior of their employees. The evaluation process is formal and informal and has a direct impact on salary increases, promotions, dismissals, transfers, and training. The ultimate goal of employee performance appraisal is to prevent and correct poor performance and to encourage good employee performance.

Two important leverages to increase productivity including optimal use of workforce and capital were considered in this model. The growth of the two factors leads to achieving organizational goals or, in other words, to increasing output in the shortest possible time. To this end, performance is studied at different levels. Depending on the research analysis type and expected objectives, the concerned level is selected and studies are performed. The highest level is the international level study and its smallest level that is examined in the social system is individual performance. Performance growth at the individual level increases productivity at the organizational level and finally at the national level. In other words, productivity growth at the national level depends on the performance growth of individual workers. Therefore, organizational objectives are set along with national goals and high-level strategies, followed by the activities that each person is determined to achieve with these goals. Furthermore, given the fact that management experts have now concluded that using teamwork is the key to solving many problems encountered by organizations and considerably increases the performance of working units, this research therefore considers separately the calculation of performance for individual work and teamwork, which is discussed in the following sections.

\subsection{Determining Activity}

The issue of organizational units' performance and, consequently, the unit's impact and finally the organization's performance is very challenging and significant. Organizations have to evaluate the activities of their units based on appropriate criteria. That is, before starting the improvement process, they must have a clear picture of their structure, because receiving accurate and true results of performance can provide a suitable basis for decision-making. Therefore, a good performance evaluation system should answer the employee's four questions:

- What is expected from me and how do I have to do it?

- Which quality am I now working with?

- What are my strengths and weaknesses (improvable)?

- How can I do my job better and increase my contribution and success?

To answer these questions in this model, the organization's objectives considering high-level documents are first determined, and then, from the numerous objectives, the principal goals of the organization are extracted. In the next step, according to the main objectives, medium-term (5 years) and annual plans are developed. Once every employee's activities are determined in accordance with organizational goals, the schedule of each activity should be specified. Moreover, the time required to 
perform each activity must be exactly measured. The time required to perform an activity considering the needed operations can be determined daily, weekly, monthly, three monthly or six monthly, or finally annually. Performance evaluation is also performed according to the same periods.

\subsection{Determining Performance Indexes}

The individual performance level is affected by many visible and invisible factors such as the type of activity, job conditions, equipment, processes, advertisement, training, and motivation, among others. All the mentioned factors are significant in their own right. However, all researchers in this field agree that, to enhance the productivity level, only one particular factor cannot be presented; they argue that, to promote productivity, the combined effect of various factors must be considered. Furthermore, considering that organizational productivity growth depends on individual performance growth and admitting the fact that each person is the only factor that can change himself/herself and make changes to his/her environment, the key role of workers, in particular, and a person, in general, is revealed in productivity. Therefore, to perform the performance evaluation of this model, eight factors were considered, which influence the main activities among the employees, by providing a questionnaire and using library resources and surveying professors and experts. These eight indexes relate to speed, accuracy, skill, creativity, interaction and coordination, communicating knowledge and experience, motivation, and expressing an idea.

Indicators determine the direction of the movement of organizations to achieve goals. Managers and assistants should determine the weight of intended indexes considering the area of activities and organizational objectives. The indexes' weights $\left(W_{k}, 1 \leq k \leq 8\right)$ are used in order to measure all of the subset people, and the sum of the weights must be equal to 100. Moreover, considering that each employee performs various activities with a different significance and complexity, weighting is done among the employee's activities. The sum of the activities' weights $\left(W_{m}^{\prime}, 1 \leq m \leq n\right)$ should be equal to 100 .

\subsection{Determining the Weight of Indexes and Activities}

Each of the managers and assistants based on the activities defined for each individual and in line with his/her capacities and abilities, as well as the importance and complexity of the duties and responsibilities, the level of expertise and skills, the scope of supervision and occupational sensitivity, education, training courses and skills, background, experience, and workload, should determine the standard score of each index $\left(X_{k}\right)$ for each person. Determining the standard value of indexes is necessary in order to determine the level of submembers' productivity. Given the value and importance degree of each index, managers and assistants have to consider a number from 1 to 10 (10 indicates the highest and 1 indicates the lowest importance degree). Each person's job standard $\left(W_{k} X_{k}\right)$ is obtained by multiplying the standard value of each index $\left(X_{k}\right)$ by the weight of the index $\left(W_{k}\right)$.

\subsection{Determining the Individual Performance Score during the Concerned Period}

The individual performance score in every index $\left(A_{k}, 1 \leq k \leq 8\right)$ considering the job he/she has done during a certain period and according to the index's importance and his/her standard score is a score from 1 to 10. To calculate an individual score in each index, the level of progress in each activity must first be determined and, according to it, the person's obtained score in every index $\left(a_{i}\right)$ is determined. The individual score obtained in each index, as shown in Table 1, is achieved using the following formula:

$$
A_{k}=\frac{\sum_{1=1}^{n} a_{i} W_{i}^{\prime}}{\sum_{1=1}^{n} W_{i}^{\prime}}
$$

\subsection{Calculating Each Person's Performance Score in Individual Work}

After determining the job standard and each person's job score, each person's performance score in every index $\left(\alpha_{k}\right)$ is calculated as $\alpha_{k}=\frac{W_{k} A_{k}-W_{k} X_{k}}{100}$ (Table 2). an employee's total performance score in individual work is equal to $\alpha=\sum \alpha_{k}$. 
Table 1. Determining the activity weights and individual score in each index. After determining the individual score, individual job score is obtained by multiplying the individual score by the indexes' weight $\left(W_{k} A_{k}\right)$.

\begin{tabular}{|c|c|c|c|c|c|c|c|c|c|}
\hline Expressing Idea & Motivation & $\begin{array}{c}\text { Communicating Knowledge } \\
\text { and Experience }\end{array}$ & $\begin{array}{c}\text { Interaction } \\
\text { and Coordination }\end{array}$ & Creativity & Skill & Accuracy & $\begin{array}{l}\text { Speed } \\
\text { (1 to 10) }\end{array}$ & $\begin{array}{c}\text { Activity } \\
\text { Weight } \\
\left(W^{\prime}\right)\end{array}$ & Activity \\
\hline & & & & & & & $a_{1}$ & $W_{1}^{\prime}$ & Activity 1 \\
\hline & & & & & & & $a_{2}$ & $W_{2}^{\prime}$ & Activity 2 \\
\hline & & & & & & & $a_{n}$ & $W_{n}^{\prime}$ & Activity $n$ \\
\hline & & & & & & & $A_{k}=\frac{\sum_{1=1}^{n} a_{i} W_{i}^{\prime}}{\sum_{1=1}^{n} W_{i}^{\prime}}$ & $\sum_{i=1}^{n} W_{i}^{\prime}=100$ & Sum \\
\hline
\end{tabular}

Table 2. Calculating the employees' performance in individual work.

\begin{tabular}{|c|c|c|c|c|c|c|}
\hline $\begin{array}{c}\text { Performance Score } \\
\alpha_{k}=\frac{W_{k} A_{k}-W_{k} X_{k}}{100}\end{array}$ & $\begin{array}{l}\text { Individual Job Score } \\
\left(W_{k} A_{k}\right)\end{array}$ & $\begin{array}{l}\text { Individual Performance Score } \\
\qquad\left(A_{k}\right)\end{array}$ & $\begin{array}{c}\text { Standard Job Score } \\
\left(W_{k} X_{k}\right)\end{array}$ & $\begin{array}{c}\text { Standard Value } \\
\left(X_{k}\right)\end{array}$ & $\begin{array}{c}\text { Weight } \\
\left(W_{k}\right)\end{array}$ & Index \\
\hline & & & & & & Speed \\
\hline & & & & & & Accuracy \\
\hline & & & & & & Skill \\
\hline & & & & & & Creativity \\
\hline & & & & & & $\begin{array}{l}\text { Communicating } \\
\text { knowledge and } \\
\text { experience }\end{array}$ \\
\hline & & & & & & Motivation \\
\hline & & & & & & Expressing idea \\
\hline$\alpha=\sum \alpha_{k}$ & & & & & & Sum \\
\hline
\end{tabular}

For performance scores to be meaningful, the score is at least 0 and at most 2 (if performance score is negative, 0 is considered, and if the score is more than 2 , then 2 is considered), as follows $\left(0 \leq \alpha=\sum \alpha_{k} \leq 2\right)$. After calculating each person's performance score in a certain period, all wages and payments for each person are paid according to the productivity score. 


\section{Calculation of Performance in Teamwork}

Teamwork enhances communication and reinforces adventure to discover increasingly more; and the capacity, power, creativity, and talent of individuals in teamwork are combined together and exponentially increased. These factors altogether result in the productivity enhancement of work. Additionally, each person has his/her own specialties and abilities. Coexistence makes these dispersed powers turn into a continuum of social and work movements and currents. Many social theorists have considered a community's capability to develop this coexistence and teamwork as one factor of progress and success to achieving high levels of productivity. Cooperative games in game theory are based exactly on teamwork and the creation of a coalition to perform jobs in groups and teams, which is explained in the following sections.

\subsection{Cooperative Games}

Cooperative games have many applications. When there is disagreement over the division and allocation of a benefit, a source, or a cost between two or more players and the competition between them threatens their interests, a logical way to model situations is to consider using cooperative games' solutions. The game characteristic form, $n$ person, is represented by $(N, V)$, in which $N=(1,2, \ldots, n)$ and $V$ is the characteristic function, representing the outcome of each coalition. Each subset of $N=(1,2, \ldots, n)$, except for an empty set, constitutes a coalition that is represented by $S$. The outcome $S$ of the coalition is equal to the sum of the individual members of coalition $S$, that is, $V(S)=\sum_{i \in S} u_{i}\left(a_{1}, \ldots, a_{n}\right)$, in which $a=\left(a_{1}, \ldots, a_{n}\right)$ is the chosen strategy of the players of the $S$ coalition. The aim is to find a coalition in which its outcome equals the maximum achievable outcome, i.e., $V(N)=\max _{a} \sum_{i=1}^{n} u_{i}(a)$.

\subsection{Shapley Method}

In this method, one attempts to allocate an outcome to each member of the coalition, which is called the Shapley value or strength of that player in the coalition [28]. The allocated value to all players is represented as a vector that is known as a vector of the value function. The Shapley value intends to pay special attention to a player's role and importance to form a coalition and to valuate it. The value assigned to members of a coalition is represented by the value function $\phi(V)=\left(\phi_{1}(V), \phi_{2}(V), \ldots, \phi_{n}(V)\right)$. $\varphi_{1}(V)$ shows a value of the i-th player in a cooperative game with a characteristic function $V$. To apply the Shapley value of a function $\varphi(V)$, the following principles should be met:

- Efficiency (group rationality), that is, $\sum_{i} \phi_{i}(V)=V(N)$.

- Symmetry; if two players $i$ and $j$ have an equal role in forming a coalition, they have to benefit equally from the coalition outcome, that is, $V(S \cup\{i\})=V(S \cup\{j\}) \Rightarrow \phi_{i}(V)=\phi_{j}(V)$.

- If one player's presence or absence in a coalition is the same, that is, he does not have a share in forming the coalition, he would not gain the coalition outcome, that is, $V(S \cup\{i\})=V(S) \Rightarrow \phi_{i}(V)=0$.

- Always $\phi(U+V) \geq \phi(U)+\phi(V)$.

If $\phi(V)$, the above principles are met; in this case, the value assigned to every player is calculated by the following relationship:

$$
\phi_{i}(V)=\sum_{\substack{S \subset N \\ i \in S}} \frac{(|s|-1) !(n-|s|) !}{n !}[V(S)-V(S-\{i\})],
$$

where $|s|$ shows the number of the coalition members, and rate of the coalition outcome $[V(S)-V(S-\{i\})]$ increases if the $i$-th member joins the coalition. 


\subsection{Collaborative Coefficient (CC)}

Considering that collaboration and participation in teamwork represent one of the main characteristics of the productivity system, and with the lack of information about the level of individuals' participation in teamwork, we propose in this model the coefficient of team collaboration in a new way, as follows:

$$
C C=2-\frac{\sum_{i=1}^{m} \frac{1}{i} F_{i}}{N}
$$

where $m$ is the number of people, $i$ is the number of subgroup members, $F_{i}$ is number of subgroups with $i$ members, and $N$ is the number of subgroups. In the presented formula, the collaborative coefficient $(C C)$ is always between 1 and $2(1 \leq C C \leq 2)$.

Example 1. Suppose that five people work for one department within an organization. The states for which the five people can constitute a team and also the coefficient of associated team collaboration are given in Table 3.

Table 3. Calculation of the group coefficient for 5 members.

\begin{tabular}{cccccccc}
\hline $\begin{array}{c}\text { Collaborative } \\
\text { Coefficient (CC) }\end{array}$ & $\begin{array}{c}\text { Number of } \\
\text { Subgroups with } \\
\text { 5 Members }\end{array}$ & $\begin{array}{c}\text { Number of } \\
\text { Subgroups with } \\
\text { 4 Members }\end{array}$ & $\begin{array}{c}\text { Number of } \\
\text { Subgroups with } \\
\text { 3 Members }\end{array}$ & $\begin{array}{c}\text { Number of } \\
\text { Subgroups with } \\
\text { 2 Members }\end{array}$ & $\begin{array}{c}\text { Number of } \\
\text { Subgroups with } \\
\text { 1 Member }\end{array}$ & $\begin{array}{c}\text { Number of } \\
\text { Subgroups }\end{array}$ & $\begin{array}{c}\text { Number of } \\
\text { Group's } \\
\text { Members }(n)\end{array}$ \\
\hline 1.8 & 1 & 0 & 0 & 0 & 0 & 1 & 5 \\
\hline 1.38 & 0 & 1 & 0 & 1 & 1 & 0 & 2 \\
\hline 1.58 & 0 & 0 & 0 & 0 & 2 & 1 & 5 \\
\hline 1.33 & 0 & 0 & 1 & 0 & 2 & 3 \\
\hline 1.22 & 0 & 0 & 0 & 1 & 3 & 5 \\
\hline 1.13 & 0 & 0 & 0 & 0 & 5 & 5 \\
\hline 1 & 0 & & & & 5 & 5 \\
\hline
\end{tabular}

Given Table 3, the possible states are as follows:

First state: A group of five people.

In this state, we have

$$
C C=2-\frac{\sum_{i=1}^{m} \frac{1}{i} F_{i}}{N}=2-\frac{\sum_{i=1}^{5} \frac{1}{i} F_{i}}{N}=2-\frac{\frac{1}{1} \times 0+\frac{1}{2} \times 0+\frac{1}{3} \times 0+\frac{1}{4} \times 0+\frac{1}{5} \times 1}{1}=2-\frac{1}{5}=1.80
$$

where we consider the table $F_{5}=1$ and $N=1$. As expected, the highest value for the collaborative coefficient occurs in this state.

Second state: A group of four people and a group of one person. In this state, the collaborative coefficient is 1.38 .

Third state: A group of three people and a group of two people. In this state, the collaborative coefficient is 1.58 that is a better state after the first state.

Fourth state: Two groups of two people and a group of one person. In this state, the collaborative coefficient is 1.33 .

Fifth state: A group of three people and two groups of one person. In this state, the collaborative coefficient is 1.22 .

Sixth state: A group of two people and three groups of one person. In this state, the collaborative coefficient is 1.33 .

Seventh state: All people act individually. In this state, the collaborative coefficient is 1 , which is the least possible value and it has the least possible effect. 


\subsection{Generalized Shapley Value}

Using the group collaborative coefficient and supposing all assumptions of the collaboration game's generalized Shapley value that is based on group, the collaborative coefficient is calculated as follows:

$$
\varphi_{i}(V)=\sum_{\substack{S \subset N \\ i \in S}} \frac{(|s|-1) !(n-|s|) !}{n !}[(V(S) \times C C)-V(S-\{i\})]
$$

where $C C$ is the group collaborative coefficient and the $[(V(S) \times C C)-V(S-\{i\})]$ rate of coalition outcome increases if a member $i$ joins the coalition.

\section{Application of the Model for Calculation and Payment of Overtime}

\subsection{Calculating the Amount of Overtime in Individual Work}

In this model, payment consists of two values considering constant and variable parts. The constant value is the same for all employees (managers can consider the value separately according to the degree of education, background, and so on and this is similar to the basis for calculating fixed salary in a public organization for each person). The variable value based on performance is calculated and paid. Each person's overtime amount is calculated from the following relation:

$$
P=K+R \times H \times \sum \alpha P=K+R \times H \times \sum \alpha
$$

where $P$ is the amount of received overtime of individual work, $K$ is the least of the overtime or fixed amount, $R$ is the rate of an individual's overtime, $H$ is the hours of an individual's overtime (presence hours), and $\sum \alpha$ is a score of an individual's activities.

Example 2. Suppose that a person's individual overtime during a month is $95 \mathrm{~h}$ and the rate of his overtime is 840 monetary units and the floor payment for overtime in the organization is 1500 monetary units. Furthermore, suppose the given scores by the manager or related official for the person's individual work is as shown in Table 4.

\begin{tabular}{|c|c|c|c|c|c|c|}
\hline $\begin{array}{c}\text { Performance Score } \\
\alpha_{k}=\frac{W_{k} A_{k}-W_{k} X_{k}}{100}\end{array}$ & $\begin{array}{l}\text { Individual Job Score } \\
\qquad\left(W_{k} A_{k}\right)\end{array}$ & $\begin{array}{l}\text { Individual Performance Score } \\
\qquad\left(A_{k}\right)\end{array}$ & $\begin{array}{l}\text { Standard Job Score } \\
\qquad\left(W_{k} X_{k}\right)\end{array}$ & $\begin{array}{l}\text { Standard Value } \\
\qquad\left(X_{k}\right)\end{array}$ & $\begin{array}{l}\text { Weight } \\
\left(W_{k}\right)\end{array}$ & Index \\
\hline 0.2 & 50 & 5 & 30 & 3 & 10 & Speed \\
\hline-0.12 & 48 & 4 & 60 & 5 & 12 & Accuracy \\
\hline 0.3 & 60 & 6 & 30 & 3 & 10 & Creativity \\
\hline 0.3 & 105 & 7 & 75 & 5 & 15 & $\begin{array}{c}\text { Interaction and } \\
\text { coordination }\end{array}$ \\
\hline 0.45 & 90 & 6 & 45 & 3 & 15 & Motivation \\
\hline 0 & 75 & 5 & 75 & 5 & 15 & Expressing idea \\
\hline$\alpha=\sum \alpha_{k}=1.28$ & & & & & & Sum \\
\hline
\end{tabular}

Table 4. Method of calculating an employee's performance score.

In this case, the person's received amount for individual overtime is as follows:

$$
P=K+\left(R \times H \times \sum a\right)=1500+95 \times 840 \times 1.28=103,644
$$

Under normal conditions, the person would have to receive 81,300 monetary units. However, given that his/her performance score is 1.28 , the model added the amount of 22,344 monetary units as a reward to his/her received amount. 


\subsection{Calculating the Amount of Overtime in Teamwork}

To calculate the group overtime amount, the group performance of each person in a group must be first determined. To this end, a table similar to Table 1 is first created. However, it must be noted that all indexes and scores given to each person are according to a job he/she has done in the group. After determining the performance score of the people in the group, the sum of group performance scores of the people is obtained. Considering that, to pay overtime, the work hours of a person should be specified, we obtain them from the following relation:

$$
H_{i}=\frac{H}{\sum_{i=1}^{n} \alpha_{i}} \times \alpha_{i}
$$

where $\alpha_{i}$ is the group performance score of group members $i, \sum_{i=1}^{n} \alpha_{i}$ is the sum of group performance scores of all people present in the group, $H$ is the total work hours of the group, $H_{i}$ is the work hours of each person in the group according to the performance score, and $n$ is the number of group members.

By multiplying the obtained work hours by the overtime rate of each person $R_{i}$, the initial received amount to each person for group work, $P_{i}$ is determined from the relation $P_{i}=H_{i} \times R_{i} \times \alpha_{i}$. In the following example, final received amounts by people are determined using the Shapley method.

Example 3. Suppose that three people participate in a group work, and their overtime rate is 850, 760, and 680 monetary units, respectively. If the total of group work hours is $95 \mathrm{~h}$, and the individuals' obtained score is according to Tables 5-7, the amount of a person's group overtime is determined.

Table 5. Scores of person 1 in teamwork.

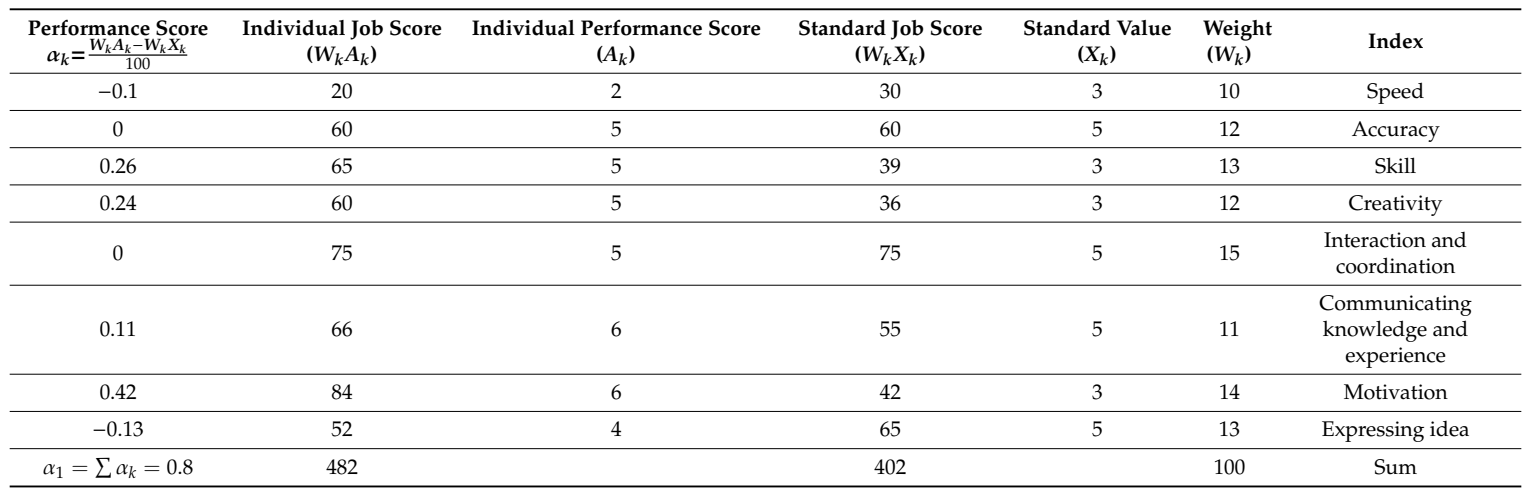

Table 6. Scores of person 2 in teamwork.

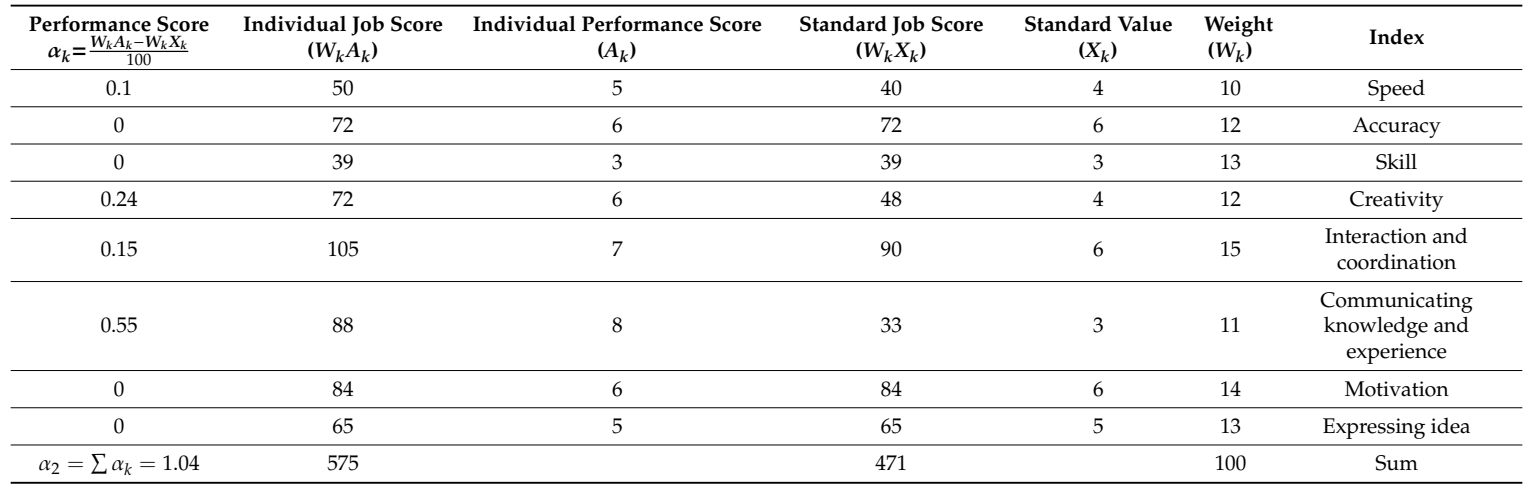


Table 7. Scores of person 3 in teamwork.

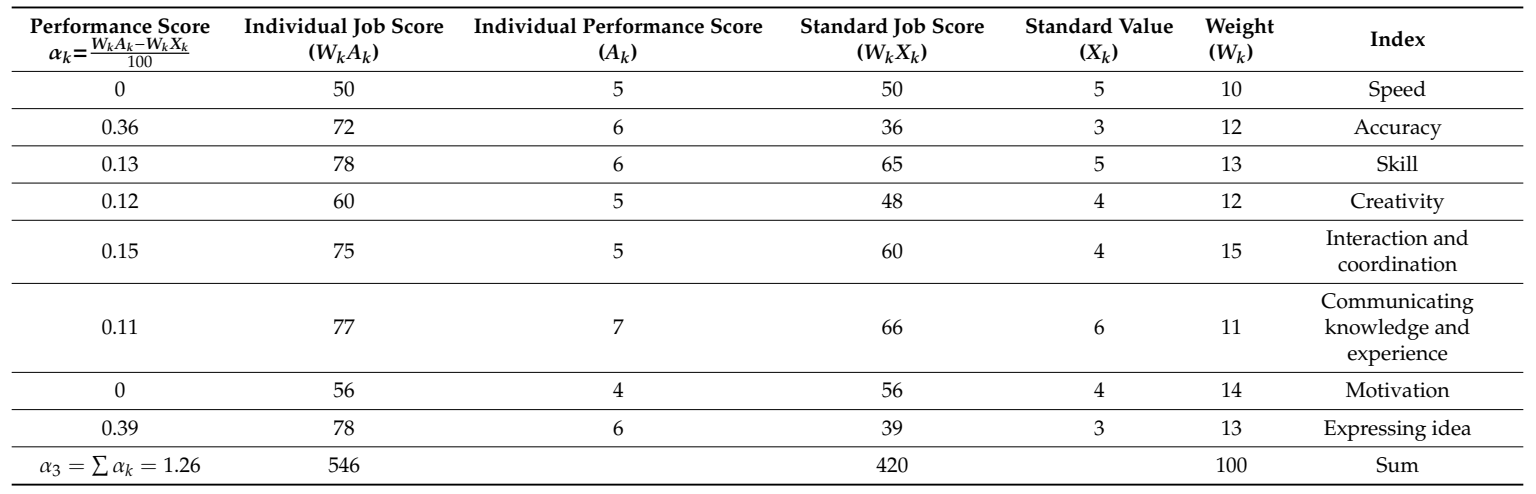

In this case, individuals' work hours for teamwork is as follows:

$$
\begin{aligned}
& H_{1}=\frac{H}{\sum_{i=1}^{3} \alpha_{i}} \times \alpha_{1}=\frac{95}{0.8+1.04+1.26} \times 0.8=24.52 \\
& H_{2}=\frac{H}{\sum_{i=1}^{3} \alpha_{i}} \times \alpha_{2}=\frac{95}{0.8+1.04+1.26} \times 1.04=31.87 \\
& H_{3}=\frac{H}{\sum_{i=1}^{3} \alpha_{i}} \times \alpha_{3}=\frac{95}{0.8+1.04+1.26} \times 1.26=38.61
\end{aligned}
$$

Consequently, initial received amounts of people from teamwork are as follows:

$$
\begin{gathered}
P_{1}=H_{1} \times R_{1} \times \alpha_{1}=24.52 \times 850 \times 0.8=16,673.7 \\
P_{2}=H_{2} \times R_{2} \times \alpha_{2}=31.87 \times 760 \times 1.04=25,190.05 \\
P_{3}=H_{3} \times R_{3} \times \alpha_{3}=38.61 \times 680 \times 1.26=33,081.05
\end{gathered}
$$

Now, we must determine each person's value in the coalitions that he/she can participate. Suppose that

\begin{tabular}{|c|c|c|c|c|}
\hline$\left.\frac{(|S|-1) !(n-|S|) !}{n !}[V(S) \times C C]-V(S-\{i\})\right]$ & $\frac{(|S|-1) !(n-|S|) !}{n !}$ & {$[V(S) \times C C]-V(\{S-\{i\})$} & $|S|$ & $\begin{array}{l}\text { Coalitions in Which } \\
\text { Player } 1 \text { Is a } \\
\text { Member }\end{array}$ \\
\hline$\frac{1}{3}(16,673.7)$ & $\frac{(1-1) !(3-1) !}{3 !}=\frac{1}{3}$ & $V(\{1\})-V(\{0\})=16,673.7$ & 1 & \\
\hline$\frac{1}{6}(27,139.63)$ & $\frac{(2-1) !(3-2) !}{3 !}=\frac{1}{6}$ & $V(\{1,2\})-V(\{2\})=27,139.63$ & 2 & \\
\hline$\frac{1}{6}(29,112.38)$ & $\frac{(2-1) !(3-2) !}{3 !}=\frac{1}{6}$ & $V(\{1,3\})-V(\{3\})=29,112.38$ & 2 & \\
\hline$\frac{1}{3}(66,137.26)$ & $\frac{(3-1) !(3-3) !}{3 !}=\frac{1}{3}$ & $V(\{1,2,3\})-V(\{2,3\})=66,137.26$ & 3 & \\
\hline $36,978.92$ & & & & $\begin{array}{l}\text { Shapley value for } \\
\text { player } 1 ; \phi_{1}(V)\end{array}$ \\
\hline
\end{tabular}
three people work for one department within an organization. Using the Shapley's generalized method, the final received amount of player 1 is calculated according to Tables 8 and 9 .

Table 8. Calculation of group coefficient for 3 members.

\begin{tabular}{cccccc}
\hline $\begin{array}{c}\text { Collaborative } \\
\text { Coefficient (CC) }\end{array}$ & $\begin{array}{c}\text { Number of } \\
\text { Subgroups with } \\
\text { 3 Members }\end{array}$ & $\begin{array}{c}\text { Number of } \\
\text { Subgroups with } \\
\text { 2 Members }\end{array}$ & $\begin{array}{c}\text { Number of } \\
\text { Subgroups with } \\
\text { 1 Member }\end{array}$ & $\begin{array}{c}\text { Number of } \\
\text { Subgroups }\end{array}$ & $\begin{array}{c}\text { Number of } \\
\text { Group's } \\
\text { Members ( } n \text { ) }\end{array}$ \\
\hline 1.666 & 1 & 0 & 0 & 1 & 3 \\
1.25 & 0 & 1 & 1 & 2 & 3 \\
1 & 0 & 0 & 3 & 3 & 3 \\
\hline
\end{tabular}

Table 9. Received amount of person 1 for teamwork. 
The cooperative games' approach more clearly defines the performance evaluation of the organization's employees. This model shows that the collaborative coefficient increases the motivation of employees to do teamwork. Each employee achieves a better result than individual work by participating in teamwork. Teamwork allows employees with fewer overtime hours to earn more than individual work. For overtime, for example, player 1's income through teamwork increased from $16,673.7$ to $36,978.92$. Similarly, the received amounts of players 2 and 3 can be determined. Player 2's income through teamwork increased from $25,190.05$ to $45,850.28$. Player 3 's income through teamwork increased from $33,081.05$ to $65,136.21$.

This study shows that the cooperative approach has a direct positive effect on the components of teamwork and organizational performance. Table 8 shows that the collaborative coefficient increases the motivation and satisfaction of employees from teamwork. Table 9 shows the results for the task cooperative approach. Thus, hypotheses 1 and 2 are supported and our results confirm the positive impact of teamwork on organizational performance improvement. Therefore, this article has obtained more confirmatory and important results compared to the works that have examined the impact of teamwork.

Point: As usual, in most cases, managers and assistants are the ones who perform a valuation of subordinate employees; therefore, this sometimes results in dissatisfaction. To prevent doubts and show more transparency, the model can be designed such that each person not only scores himself/herself and colleagues but also provides scores for his/her high-level authority. In this case, a game is taking place among them that, in the long term, results in more collaboration. Of course, to prevent any anxiety it must be planned, so that access to the given scores is limited and, in some cases, only the office's or organization's administrator can view the individual's scores and information.

\section{Discussion and Conclusions}

One application of this model, which is in direct relationship with the organization's reward system, provides a strong motivation for employees to attempt creatively to achieve the organizational objectives. As long as the model is implemented properly, it not only allows the employees to know their current performance quality but also makes clear the measures that they have to follow in order to improve their performance. Furthermore, it creates effective communications between employees and authorities and enhances their motivation for teamwork. Moreover, the model results can be applied widely for compensation, performance improvement, and documentation. Therefore, its results can be used for decisions related to employees (such as promotion, transition, firing, and secondment), analysis of training requirements, employees' development, and research and plan valuation. A summary of the objectives that are achieved by implementing the model presented in this article is provided in the following table (Table 10).

Table 10. Organizational objectives that are achieved by implementing the model.

\begin{tabular}{|llll|}
\hline & \multicolumn{2}{|c}{ Development Objectives } & \multicolumn{1}{c|}{ Administrative Objectives } \\
\hline- & providing performance feedback & - & documentation of decisions related \\
- & identifying strengths and weaknesses & & to employees \\
- & recognizing people performance & - & determination of assignments and tasks \\
- & helping to identify objectives & - & identification of weak performance \\
- & evaluating the rate of access to objectives & - & decision on firing, maintaining, or promotion \\
- & identifying individual training requirements & - & evaluation of training plans \\
- & identifying organizational & - & decision on rewards and compensations \\
& training requirements & - & compliance with regulations \\
- & improving communications & - & personnel planning \\
\hline
\end{tabular}

The model allows for interesting results, reaching the objectives intended by its implementation.

The present study offers a wide set of implications in different dimensions, making it possible for organizations to easily achieve performance improvement, based on a game cooperative approach. 
Our methodology is theoretically very relevant for companies, and its practical application in companies is presently the subject of our research. A study is currently being applied to companies, and practical results are expected after its period of implementation.

Author Contributions: All the authors contributed to conceptualization, formal analysis, investigation, methodology, writing - original draft, and writing - review and editing. All authors have read and agreed to the published version of the manuscript.

Funding: This research received no external funding.

Acknowledgments: This article has been extracted from the project of Game theory and its application in sciences (Iran National Science Foundation, No. 96002125).

Conflicts of Interest: The authors declare no conflict of interests.

\section{References}

1. Shirouyehzad, H.; Tavakoli, M. Ranking the branches of a private bank through the service quality gap approach and by using multi criteria decision making. Int. J. Prod. Qual. Manag. 2013, 12, 327-344.

2. Collings, D.; Scullion, H. Talent management: Progress and prospects. Hum. Resour. Manag. Rev. 2014, 25, 233-235. [CrossRef]

3. Eccles, R.G. The performance measurement manifesto. Harv. Bus. Rev. 1977, 69, 131-138.

4. Pambreni, Y.; Khatibi, A.; Azam, S.; Tham, J. The influence of total quality management toward organization performance. Manag. Sci. Lett. 2019, 9, 1397-1406. [CrossRef]

5. Hersey, P.; Blanchard, K.H.; Johnson, D.E. Management of Organizational Behavior; Prentice Hall: Upper Saddle River, NJ, USA, 2007.

6. Tuckman, B.W. Developmental sequence in small groups. Psychol. Bull. 1965, 63, 384-399. [CrossRef] [PubMed]

7. Flores-Szwagrzak, K.; Treibich, R. Teamwork and individual productivity. Manag. Sci. 2020, 66, 1212-1227. [CrossRef]

8. Hanaysha, J. Testing the effects of employee empowerment, teamwork, and employee training on employee productivity in higher education sector. Int. J. Learn. Dev. 2016, 6, 164-178.

9. Agarwal, S.; Adjirackor, T. Impact of teamwork on organizational productivity in some selected basic schools in the Accra metropolitan assembly. Eur. J. Bus. Econ. Account. 2016, 4, 40-52.

10. Diamantidis, A.D.; Chatzoglou, P. Factors affecting employee performance: an empirical approach. Int. J. Product. Perform. Manag. 2019, 68, 171-193. [CrossRef]

11. Hamilton, B.H.; Nickerson, J.A.; Owan, H. Team incentives and worker heterogeneity: an empirical analysis of the impact of teams on productivity and participation. J. Polit. Econ. 2003, 111, 465-497. [CrossRef]

12. Bacon, N.; Blyton, P. The impact of teamwork on skills: Employee perceptions of who gains and who loses. Hum. Resour. Manag. J. 2003, 13, 13-29. [CrossRef]

13. Melo, C.D.; Cruzes, D.S.; Kon, F.; Conradi, R. Interpretative case studies on agile team productivity and management. Inf. Softw. Technol. 2013, 55, 412-427. [CrossRef]

14. Khan, S.; Mashikhi, L.S. Impact of teamwork on employee's performance. Int. J. Educ. Soc. Sci. 2017, 4, 14-22.

15. Sanyal, S.; Hisam, M.W. The impact of teamwork on work performance of employees: A study of faculty members in Dhofar University. IOSR J. Bus. Manag. 2018, 20, 15-22.

16. Karanja, E.W.; Muraguri, C.; Kinyua, G. Effects of Teamwork on Performance of the Water Service Regulatory Board. Strateg. J. Bus. Chang. Manag. 2018, 5, 1-6.

17. Rajabali, A.; Reuben, J.M. The Effect of Teamwork Development on Organizational Performance: A Case Study of Tile and Carpet Centre in Kenya. Glob. Sci. J. 2019, 7, 542-558.

18. Abuzid, H.F.T.; Abbas, M. Impact of Teamwork Effectiveness on Organizational Performance Vis-a-Vis Role of Organizational Support and Team Leader's Readiness: A Study of Saudi Arabian Government Departments Work Teams. Int. Bus. Manag. 2017, 100, 683-691.

19. Austin, J.R. Transactive memory in organizational groups: The effects of content, consensus, specialization, and accuracy on group performance. J. Appl. Psychol. 2003, 88, 866-878. [CrossRef]

20. Ooko, P.; Odundo, P. Impact of teamwork on the achievement of targets in organisations in Kenya. A case of SOS children's villages ELDORET. Eur. J. Bus. Manag. 2015, 7, 69-77.

21. Von Neumann, J.; Morgenstern, O. Theory of Games and Economic Behavior; Princeton University Press: Princeton, NJ, USA, 1953. 
22. Nash, J.F. Non-cooperative games. Ann. Math. 1951, 54, 286-295. [CrossRef]

23. Nash, J.F. Equilibrium points in n-person games. Proc. Natl. Acad. Sci. USA 1950, 36, 48-49. [CrossRef] [PubMed]

24. Askari, G.; Eshaghi Gordji, M.; Park, C. The behavioral model and game theory. Palgrave Commun. 2019, 5, 1-8. [CrossRef]

25. Eshaghi Gordji, M.; Askari, G. Dynamic system of strategic games. Int. J. Nonlinear Anal. Appl. 2018, 9, 83-98.

26. Munim, Z.H.; Saeed, S.; Larsen, O.L. 'Tool port' to 'landlord port': A game theory approach to analyse gains from governance model transformation. Marit. Policy Manag. 2019, 46, 43-60. [CrossRef]

27. Xiao, Y.; Hipel, K.W.; Fang, L. Incorporating water demand management into a cooperative water allocation framework. Water Resour. Manag. 2016, 30, 2997-3012. [CrossRef]

28. Shapley, L.S. A Value for $\mathrm{n}-$ Person Games. In Contributions to the Theory of Games; Princeton University Press: Princeton, NJ, USA, 1953; pp. 307-317.

29. Shubik, M. The dollar auction game: A paradox in non-cooperative behavior and escalation. J. Confl. Resolut. 1971, 15, 109-111. [CrossRef]

30. Mahfouz, S.A. TQM practices and organizational performance in the manufacturing sector in Jordan: The mediating role of HRM practices and innovation. J. Manag. Oper. Res. 2019, 1, 1-12.

31. Evans, J.R. Quality \& Performance Excellence: Management, Organization, and Strategy, 8th ed.; Cengage Learning: Boston, MA, USA, 2011.

Publisher's Note: MDPI stays neutral with regard to jurisdictional claims in published maps and institutional affiliations.

(C) 2020 by the authors. Licensee MDPI, Basel, Switzerland. This article is an open access article distributed under the terms and conditions of the Creative Commons Attribution (CC BY) license (http://creativecommons.org/licenses/by/4.0/). 